\title{
Possibility of Diabetes Prevention by High-amylose Rice and Super Hard Rice
}

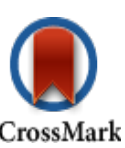

\author{
Kenichi Ohtsubo $^{1 *}$, Sumiko Nakamura ${ }^{1}$, Satoshi Maeda ${ }^{1,2}$, Atsushi Kobayashi ${ }^{2}$, Akira Yamazaki ${ }^{2}$, Shaw \\ Watanabe $^{3}$
}

${ }^{1}$ Department of Applied Biology Chemistry, Niigata University, Japan

${ }^{2}$ Echigo Seika Co. Ltd., Nagaoka, Japan

${ }^{3}$ Life Science Promotion Foundation, Daikyo-cho, Shinjuku-ku, Tokyo, Japan

*Corresponding author: Kenichi Ohtsubo, Department of Applied Biology Chemistry, Faculty of Agriculture, Niigata University, Japan, E-mail: ohtsubok@agr.niigata-u.ac.jp

\begin{abstract}
Diabetes is one of the most devastating diseases in the world. Its prevention is very important in addition to the development of the curing technology. We started the cooperative research on low Glycemic Index (GI) rice to prevent diabetes. High-amylose rice is promising to prevent diabetes because its GI is lower than low-amylose one.

Since Hoku243 presents fewer short-branched glucans and more long chains in the amylopectin starch, its starch is resistant to gelatinization and the boiled rice grains are non-sticky and brittle. The prevention of abrupt increases in postprandial blood glucose level (BGL) by feeding Sprague-Dawley (SD) rats with Hoku243 (produced by high pressure treatment (HPT) after soaking in unsalted rice koji miso) was investigated.
\end{abstract}

Received date: December 23, 2015

Accepted date: February 18, 2016

Published date: February 22, 2016

Citation: Ohtsubo, K., et al. Possibility of Diabetes Prevention by High-amylose Rice and Super Hard Rice. (2016) J Diabetes Obes 3(1): 1-7.

DOI: $10.15436 / 2376-0949.16 .728$

\section{Introduction}

Diabetes is a lifestyle disease and, hence, its prevention and management are extremely important. Low glycemic index (GI) foods inhibit the rapid increase in blood glucose or insulin secretion after a meal. Several studies have highlighted high-resistant starch (RS $)^{[1,2]}$ or high-amylose and high-dietary fiber rice ${ }^{[3]}$ that was developed by physical or chemical mutation. Animal and clinical studies indicated that indigestible dextrin (ID) $)^{[4]}$ has physiological roles such as regulating the functions of the intestines, modulating postprandial BGL, lowering serum lipids, and reducing body fat. High-amylose rice and super hard rice (amylopectin long chain rice) is promising to prevent diabetes because its GI is lower than ordinary low-amylose one ${ }^{[5]}$.

Amylose-extender (Ae) mutant rice cultivar, Hokurikukona243 (Hoku243), has been developed by the National Agricultural and Food Research Organization (NARO). Although Hoku243 lacks starch-branching enzyme (BE) IIb, which leads to a decrease in short-chain glucans (a degree of polymerization (DP) $<17$ ), the proportion of longer chains (DP $\geq 37$ ) was lower than the other ae mutant rice $e^{[]]}$. The glycemic effect of foods depends on numerous factors such as the amylose and amylopectin structure. The amylopectin of ae mutants presents more long-chain glucans, thereby making the texture of the rice grains very hard and non-sticky after cooking and rendering it unpalatable as cooked rice ${ }^{[7-9]}$. The gelatinization temperatures of ae mutant rice starches are very high, ae mutant rice contains a substantial amount of RS even after boiling, ${ }^{[10,11]}$ making it a material for low-GI foods such as bread and noodles, so as to prevent diabetes. Furthermore, the batter made from ae mutant rice flour absorbed less oil during frying compared with that made from wheat flour and other types of rice flour ${ }^{[12]}$.

High pressure treatment (HPT) is very useful in the food industry ${ }^{[13]}$. HPT is the technological process that has the least effect on tested hydrosoluble vitamins, thus contributing to the preservation of the nutritional quality in foodstuffs ${ }^{[14,15]}$. Yun et al. ${ }^{[16]}$ showed that the HPT process could be a suitable alternative to traditional pretreatment for improving boiled rice flavor. The combination of high pressure and protease treatments is effective for the removal of allergenic proteins from rice grains ${ }^{[17]}$. Gamma aminobutyric acid (GABA), a bio-functional component in brown rice, is increased by HPT ${ }^{[18]}$. Yamakura et al. ${ }^{[19]}$ showed that HPT before cooking results in an increase in some free amino acids and stickiness of cooked rice.

We attempted to develop a new method to improve the texture of Hoku243 boiled rice grains, which maintaining the high RS and dietary fiber content of boiled rice by the combination of HPT and soaking in unsalted rice koji miso (unsalted miso). Al- 
though the ae mutant, Hoku243, is not suitable as boiled rice and as a staple food because of its low palatability, it would be promising material for palatable and bio-functional food such as a low GI food after HPT and soaking in miso ${ }^{[20]}$.

\section{Materials and Methods}

\section{Materials}

High-amylose rice (Yumetoiro, Hoshiyutaka, Chugoku134 ${ }^{[21]}$ and low-amylose rice (Milky queen, Koshihikari) were subjected to the analyses. The ae mutant cultivar, Hoku243, and high-quality premium rice Koshihikari were cultivated in an experimental field at Hokuriku Research Center in the Central Agricultural Research Center, NARO, Japan in 2013. All rice samples were stored at $4^{\circ} \mathrm{C}$ before the experiments.

Preparation of rice samples: Brown rice was polished using an experimental friction-type rice milling machine (Yamamotoseisakusyo Co., Yamagata, Japan) to a milling yield of $90-91 \%$. The rice flour used in chemical analyses and to evaluate the pasting properties was prepared by an SFC-S1 cyclone mill (Udy, Fort Collins, CO, USA) with a screen with 1-mm diameter pores.

Proximate compositions: Moisture content was measured by the AOAC official method ${ }^{[22]}$ (oven dry method, $135^{\circ} \mathrm{C}, 3 \mathrm{~h}$ ). Nitrogen content was measured by the AOAC official method ${ }^{[23]}$ (Kjeldahl method) and protein content was calculated by multiplying nitrogen-protein conversion coefficient, 5.95. Fat content was determined by the AOAC official method ${ }^{[24]}$ (acid hydrolysis method). Ash was measured by the AOAC official method ${ }^{[25]}$ (direct ashing method). Carbohydrate was calculated by the difference method. Amylose content was measured by the Iodine colorimetric method by Juliano ${ }^{[26]}$.

Preparation of cooked rice samples: Polished rice grains $(100 \mathrm{~g})$ were added to $140 \mathrm{~g}(1.4$ times, w/w) of distilled water (DW) at $15^{\circ} \mathrm{C}$, and the control sample (Koshihikari, $100 \mathrm{~g}$ ) were added to $130 \mathrm{~g}\left(1.3\right.$ times, w/w) of DW before soaking for $1 \mathrm{~h}$ at $15^{\circ} \mathrm{C}$. The samples were then boiled in a KSHA5 electric rice cooker (SHARP, Osaka, Japan). The boiled rice samples were kept in the vessel for $2 \mathrm{~h}$ at $25^{\circ} \mathrm{C}$ and then used for the measurements. Similarly, Hoku243 (100 g) were soaked in $0.5 \%$ unsalted miso suspension 140 $\mathrm{g}\left(1.4\right.$ times, w/w) for $0.5 \mathrm{~h}$ at $55^{\circ} \mathrm{C}$, followed by treatment at $200 \mathrm{MPa}$ for 2 min in an $\mathrm{HP}$ machine (Ishikawajima-Harima Heavy Industries Co., Ltd., Tokyo, Japan) and boiling in a rice cooker (sample F). After blending, milled rice grains of Hoku243 and Koshihikari (2:1 ratio, w/w; HK $100 \mathrm{~g})$ were soaked in $0.5 \%, 1.0 \%$, and $2.0 \%$ unsalted miso suspension $(140 \mathrm{~g}, 1.4 \mathrm{times}$, w/w) for $0.5 \mathrm{~h}$ at $55^{\circ} \mathrm{C}$, respectively, and subjected to HPT and boiling in a rice cooker (samples C, D, and E, respectively).

The boiled rice samples were stored in a freezer at $-80^{\circ} \mathrm{C}$. Subsequently, each sample was lyophilized using a freeze dryer (FD-1, Eyela, Tokyo, Japan) before pulverization using an SFC-S1 cyclone mill with a screen with 1-mm diameter pores.

Measurement of resistant starch (RS): The RS in the samples was measured according to the slightly modified AOAC method by a resistant starch assay kit (Megazyme, Wicklow, Ireland) ${ }^{[27]}$. Each sample (100 mg) was digested by pancreatin and amyloglucosidase at $37^{\circ} \mathrm{C}$ for $6 \mathrm{~h}$ (reduced from $12 \mathrm{~h}$ to $6 \mathrm{~h}$ ) and the glucose content was measured using a spectrophotometer at $510 \mathrm{~nm}$. The boiled rice flour samples were prepared by pulverization after lyophilization.

Measurement of physical properties: Physical properties of cooked rice grains were measured with a Tensipresser (My boy system, Taketomo Electric Co. Tokyo) according to the method of Okadome et al. ${ }^{[28]}$ The physical properties of hardness and stickiness in a surface layer and an overall layer of a single cooked rice grain were measured using the low-compression test (LCT) and high compression test (HCT), respectively. The compression ratio of LCT was $25 \%$, which caused a small deformation in the thickness of the grain, whereas HCT was $90 \%$, at which the grain was compressed almost completely with great deformation as shown in Figure 1.

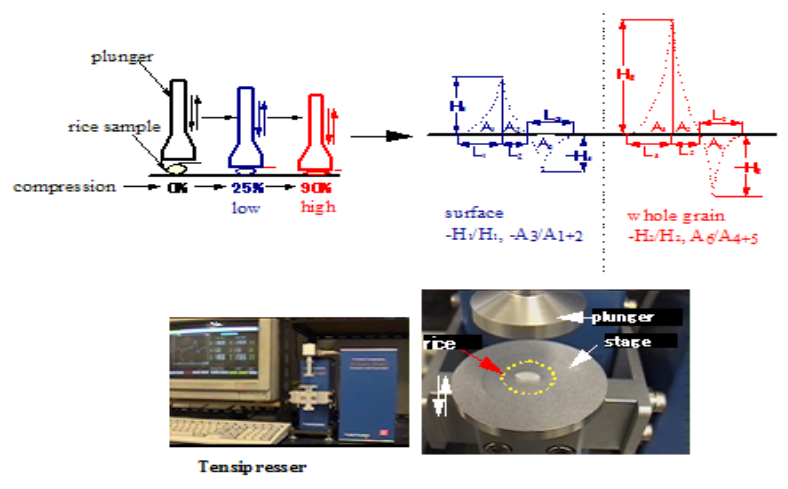

Figure 1: Physical property measures by a Tensipresser 


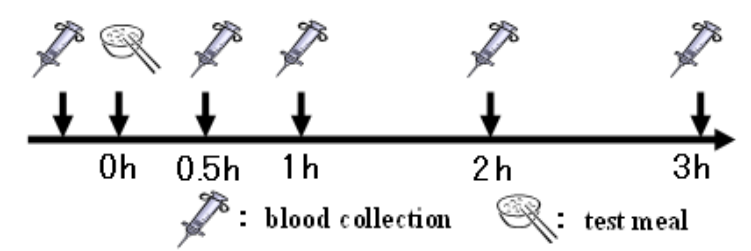

-Test meal was served with water and finished after 15 minutes.

- Mastication was $30-40$ times for each mouthful rice

\section{Items for blood test}

blood sugar, insulin, total chol esterol (TC), LDL-chol esterol (LDL), HDL cholesterol (HDL), total neutral glycerol (TG)

bio-markers such as GLP-1

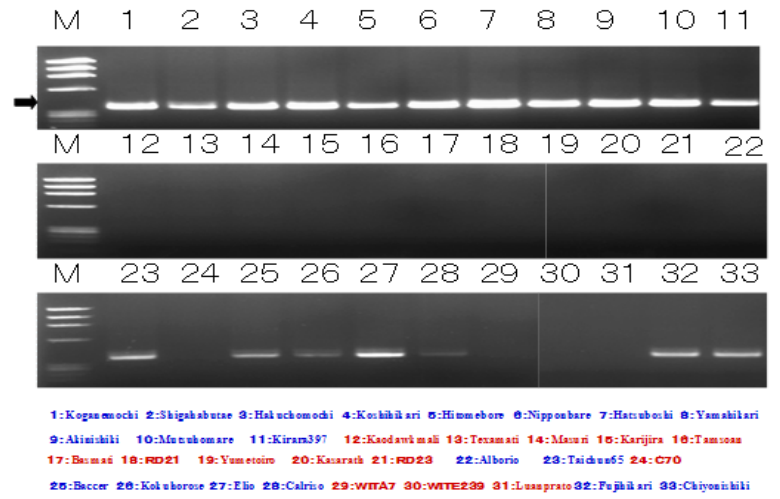

Figure 3: Development of PCR prier using the Japonica- specific starch de-branching enzyme primers

The physical properties of boiled rice (Hoku243, super hard rice) grains were measured based on bulk measurement (10 g), using a My Boy System Tensipresser (Taketomo Electric Co., Tokyo, Japan) according to the method described by Odahara et al. The bulk measurements were repeated five times, and the mean value was calculated.

Taste Analyzer: Cooked rice grains of Koshihikari, Hoshiyutaka, Yumetoiro and Chugoku134 were molded and subjected to the measurement of palatability with a Taste Analyzer (Satake Inc., Higashihiroshima, Japan).

Pasting property: Pasting properties of rice flours were measured with a Rapid Visco Analyzer (DVA-3D, Newport Scientific., Warriewood, Australia). The measurement was carried out according to our previous report ${ }^{[29]}$.

DNA analyses: According to the CTAB method, DNAs of the milled rice flours were extracted, purified and used as template DNAs for PCR ${ }^{[30]}$ (polymerase chain reaction). DNAs were amplified by the PCR method using DBE-J primers (forward primer; TAGCATGATCGCATTATCCCAGGTC, reverse primer; AATGAACATTGTGTGCTCATCTTAC) as described in our previous report ${ }^{[31]}$. The template DNAs were denatured for $1 \mathrm{~min}$ at $94^{\circ} \mathrm{C}$ annealed for $1 \mathrm{~min}$ at $62^{\circ} \mathrm{C}$ and elongated for $2 \mathrm{~min}$ at $72^{\circ} \mathrm{C}$ using a Thermal Cycler (Dice, Takara-bio Inc., Ohtsu, Japan). This procedure was repeated 40 times. Amplified DNAs were subjected to the electrophoresis for $30 \mathrm{~min}$ through the agarose gel (2\%) using a Mupid-2 electrophoresis system (Cosmo-bio, Tokyo, Japan) at the charge of a direct current of $100 \mathrm{~V}$. After the electrophoresis, the DNA was stained by ethidium bromide and detected by irradiation of UV light.

In vitro digestion test: Cooked rice grains $(2 \mathrm{~g})$ were mushed in mortar, followed by amylase digestion, gluco-amylase digestion and the amount of generated glucose were spectrophotometrically measured as shown in figure 4 .

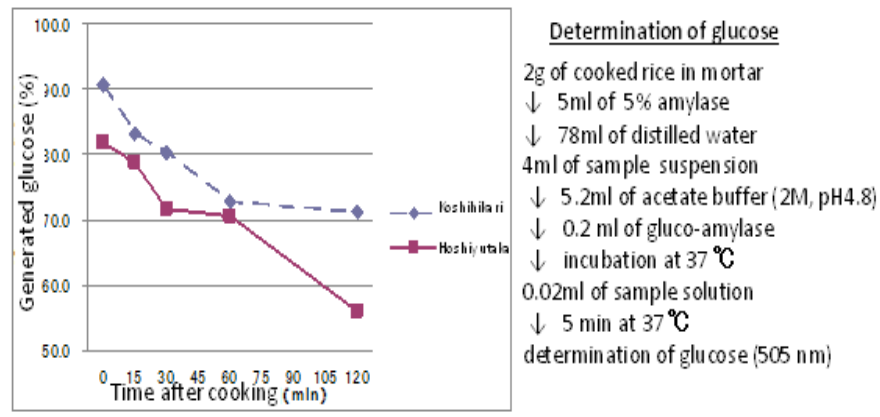

Figure 4: Change in retrogradation after cooking

Feeding test of rats: Five-week-old Sprague-Dawley (SD) male rats were obtained from Japan SLC, Inc. Rats were housed individually in an air-conditioned room at $23-24^{\circ} \mathrm{C}$ under a 12-h light cycle. After acclimatization with a commercial rodent diet (MF, Oriental Yeast, Tokyo, Japan) for $7 \mathrm{~d}$, the rats were divided into 5 groups of 6 rats each. Potato starch $(200 \mathrm{mg} / \mathrm{mL} / \mathrm{DW})$ was autoclaved for $5 \mathrm{~min}$ at $95^{\circ} \mathrm{C}$, and then mixed with sample rice flour $(200 \mathrm{mg} / \mathrm{mL} / \mathrm{DW})(1: 1)$. This mixture was given orally in a single dose through a gastric tube $(20 \mathrm{~mL} / \mathrm{kg})$. The BGL was measured at $30 \mathrm{~min}, 60 \mathrm{~min}, 90 \mathrm{~min}$, and $120 \mathrm{~min}$ after feeding using an Accu-Chek Aviva (Roche Diagnostics, Mannheim, Germany). The blood glucose response curve and area under the curve (AUC) were also calculated. The animal feeding test was conducted with the formal approval of the Ethics Committee on Animal Care according to the "Guide for the Care and Use of Laboratory Animals" of the Japan Food Research Laboratories.

Cooked rice grains of low-amylose rice, Koshihikari and high-amylose rice, Hoshiyutaka were subjected to the feeding test. Both kind of rice grains were fed at 20 min or 2 hours after cooking. 


\section{Diet tests by human}

Analysis of expiratory gas after meal: Hydrogen gas in the expiratory gas is an index for the undigested substances digested by the microorganisms in large intestine.

Diet test: Subjects: 10 healthy persons (9 Males and 1 Female)

Design of experiments: Cross over design (Wash out periods is more than 1 week)

Meals: Ordinary cooked rice, cooked rice of high-amylose rice both of and correspond to $50 \mathrm{~g}$ of sugar (about $160 \mathrm{~g}$ : one bawl of cooked rice).

Test meal was served with water and finished after 15 minutes, and mastication was 30-40 times for each mouthful boiled rice grains.

Blood sugar, insulin, total cholesterol (TC), LDL-cholesterol (LDL), HDL cholesterol (HDL), total neutral glycerol (TG) and bio-markers such as GLP-1Glucose and insulin in the blood vessels were measured at the interval of 30 minutes after the meal.

This test was carried out under the supervision of medical doctors based on the spirit of Helsinki Declaration with the permission of Ethical Committee of Tokyo Jikei Medical University

\section{Results and Discussion}

\section{Proximate compositions}

Proximate composition of the rice samples was measured. High-amylose rice, Hoshiyutaka showed higher amylose of $30 \%$ as shown in Table 1.

Table 1: Nutritional and physical properties of samples

\begin{tabular}{|c|c|c|c|c|}
\hline \multicolumn{5}{|c|}{ Nutritional components } \\
\hline Components/rice samples & $\begin{array}{c}\text { Koshihikari } \\
\text { (Low-amylose) }\end{array}$ & $\begin{array}{c}\text { Yumetoiro } \\
\text { (High-amylose) }\end{array}$ & $\begin{array}{c}\text { Hoshiyutaka } \\
\text { (High-amylose) }\end{array}$ & $\begin{array}{c}\text { Chugoku } 134 \\
\text { (High-amylose) }\end{array}$ \\
\hline Moisture & $15.70 \%$ & $15.20 \%$ & $14.80 \%$ & $14.60 \%$ \\
\hline Protein & 6.3 & 6.7 & 5.2 & 6.3 \\
\hline Fat & 0.9 & 1.2 & 1.3 & 1.6 \\
\hline Ash & 0.4 & 0.5 & 0.5 & 0.6 \\
\hline Carbohydrate & 76.7 & 76.4 & 78.2 & 76.9 \\
\hline Amylose & 17.8 & 31.2 & 29.7 & 28.7 \\
\hline \multicolumn{5}{|c|}{ Pasting properties of rice samples by RVA } \\
\hline Properties/rice samples & $\begin{array}{c}\text { Koshihikari } \\
\text { (Low-amylose) }\end{array}$ & $\begin{array}{c}\text { Yumetoiro } \\
\text { (High-amylose) }\end{array}$ & $\begin{array}{c}\text { Hoshiyutaka } \\
\text { (High-amylose) }\end{array}$ & $\begin{array}{c}\text { Chugoku } 134 \\
\text { (High-amylose) }\end{array}$ \\
\hline Peak viscosity & 379RVU & 373RVU & 235RVU & 203RVU \\
\hline Break down & 224 & 127 & 99 & 58 \\
\hline Consistency & 115 & 264 & 193 & 187 \\
\hline Retro Index & 72 & 171 & 111 & 116 \\
\hline
\end{tabular}

\section{Measurement of physical properties}

On the version-up of the RVA, we developed novel software to estimate the degree of retrogradation based on the data of pasting properties. High-amylose rice showed higher"retro-index" than low-amylose one as shown in Table 1.

\section{Texture and palatability of cooked rice grains}

Textures of cooked rice prepared from high-amylose rice were compared with those from low-amylose rice, Koshihikari. Cooked rice from high-amylose rice is hard and non-sticky. Palatability of cooked rice from high-amylose rice is inferior to that from low-amylose one as shown in Table 2.

\section{Physical properties of Hoku243 boiled rice}

Table 3 shows the physical properties of the boiled rice grains by the bulk measurement $(10 \mathrm{~g})$ with the Tensipresser. ${ }^{[28]}$ Hoku243 boiled rice grains after HPT and soaking in the miso suspension (sample F) were softer and stickier than that of Hoku243 as control (sample B), while their hardness and toughness were lower than those of Hoku243 as control (sample B). Moreover, the ratio of hardness to stickiness of the Hoku243 boiled rice was decreased 0.6 times by HPT after soaking in $0.5 \%$ unsalted miso for $0.5 \mathrm{~h}$ at $55^{\circ} \mathrm{C}$ (sample F), compared with the control Hoku243 soaked in DW. The ratio of hardness to adhesion of the Hoku243 boiled rice showed a similar value. 
Table 2: Texture and palatability of cooked rice grains

\begin{tabular}{|c|c|c|c|c|}
\hline \multicolumn{5}{|c|}{ Texture of cooked rice by Tensipresser } \\
\hline Parameters/rice samples & $\begin{array}{c}\text { Koshihikari } \\
\text { (Low-amylose) }\end{array}$ & $\begin{array}{c}\text { Yumetoiro } \\
\text { (High-amylose) }\end{array}$ & $\begin{array}{c}\text { Hoshiyutaka } \\
\text { (High-amylose) }\end{array}$ & $\begin{array}{c}\text { Chugoku } 134 \\
\text { (High-amylose) }\end{array}$ \\
\hline Surface hardness & 81.5 & 93.4 & 93.4 & 85 \\
\hline stickiness & 19.6 & 2.69 & 2.5 & 3.46 \\
\hline Adhesion & 1.24 & 0.27 & 0.17 & 0.25 \\
\hline Overall hardness & 2140 & 3120 & 2760 & 2750 \\
\hline stickiness & 500 & 180 & 240 & 250 \\
\hline Adhesion & 1.9 & 1.03 & 0.43 & 0.42 \\
\hline \multicolumn{5}{|c|}{ Palatability of rice samples } \\
\hline Parameters/rice samples & $\begin{array}{c}\text { Koshihikari } \\
\text { (Low-amylose) }\end{array}$ & $\begin{array}{c}\text { Yumetoiro } \\
\text { (High-amylose) }\end{array}$ & $\begin{array}{c}\text { Hoshiyutaka } \\
\text { (High-amylose) }\end{array}$ & $\begin{array}{c}\text { Chugoku } 134 \\
\text { (High-amylose) }\end{array}$ \\
\hline Palatability & 82 & 30 & 32 & 33.7 \\
\hline Whiteness & 42 & 40.6 & 35.7 & 32 \\
\hline Appearance & 8.5 & 0.2 & 0.8 & 1.2 \\
\hline
\end{tabular}

The hardness and toughness of the boiled rice blend (sample C, D, and E) decreased to 0.5-0.7 times compared with Hoku243 as control (sample B), and adhesion and stickiness of the boiled rice blend (sample C, D, and E) increased to 1.2-2.7 times when compared to that of Hoku243 as control (sample B).

As shown in Table 3, Hoku243 boiled rice grains soaked in DW without HTP (sample B) showed a harder and less sticky texture compared with Koshihikari rice (sample A). The group of high-amylose starches includes two types of rice starches with similar apparent amylose contents (AAC), but different super-long chain (SLC) amylopectin contents ${ }^{[32]}$. The cooked grains of ae mutant rice cultivars are too hard and non-sticky, because ae mutant rice cultivars lack the starch branching enzyme-IIb and contain amylopectin that consists of long-chain glucans ${ }^{[7-9]}$.

The application of HPT to indica rice grains changed the cooking properties as well as enzymatic treatments. Therefore, HPT can be applied to the production of boiled indica rice, which would be acceptable for Japanese customers ${ }^{[28]}$. Yamakura et al. ${ }^{[19]}$ showed that treatment of boiled rice at $400 \mathrm{MPa}$ for $10 \mathrm{~min}$ increased the ratio of stickiness to hardness. One of the characteristics of ae mutant rice cultivars is that their grains are chalky and not transparent. Therefore, we consider that the decrease in hardness and increase in stickiness were accelerated from the structure of the chalky grain structure.

\section{DNA analyses}

- Difference in DNA structure of starch de-branching enzyme between Indica/Japonica rice was shown in Figure 3.

- Development of PCR primer using the Japonica-specific starch de-branching enzyme primers was shown to be useful to differentiate high and low-amylose rice.

\section{Feeding test of rats:}

Retrogradation of the gelatinized starch proceeds after cooking was observed. And difference in digestibility between high- and low-amylose rice is enlarged by the retrogradation of starch as shown in Figure 4.

\section{Changes in postprandial blood glucose level in rats fed with super hard rice, Hoku243.}

As shown in Figure 5 (a), sample C showed the highest BGL and sample B showed the lowest BGL, and only these two samples showed a significant difference. As shown in Table 3, sample B boiled rice grains were the hardest and the least sticky. In contrast, sample $\mathrm{C}$ boiled rice grains showed the lowest hardness and toughness. It seems that the hardness of the boiled rice grains markedly affects the BGL during the early stage of digestion.

Table 3: Physical properties of Hoku243 boiled rice

\begin{tabular}{|c|c|c|c|c|c|c|c|c|}
\hline & $\begin{array}{l}\text { Hardness } \\
{\left[\mathrm{gw} / \mathrm{cm}^{2}\right]}\end{array}$ & SD & $\begin{array}{l}\text { Toughness } \\
{\left[\mathrm{gw} / \mathrm{cm}^{2}\right]}\end{array}$ & $\mathrm{SD}$ & $\begin{array}{l}\text { Adhesion } \\
{\left[\mathrm{gw} / \mathrm{cm}^{2}\right]}\end{array}$ & $\mathrm{SD}$ & $\begin{array}{l}\text { Stickiness } \\
{\left[\mathrm{gw} / \mathrm{cm}^{2}\right]}\end{array}$ & $\mathrm{SD}$ \\
\hline A: Kos by soaking in DW for $1 \mathrm{~h}-15^{\circ} \mathrm{C}$ & $11.34 \mathrm{a}$ & 1.92 & $30.66 \mathrm{a}$ & 3.73 & $40.30 \mathrm{a}$ & 4.11 & $46.25 \mathrm{a}$ & 3.02 \\
\hline B: $\mathrm{H} 243$ by soaking in DW for $1 \mathrm{~h}-15^{\circ} \mathrm{C}$ & $17.24 \mathrm{~b}$ & 1.59 & $39.99 \mathrm{~b}$ & 1.69 & $12.57 \mathrm{~b}$ & 3.5 & $14.43 \mathrm{~b}$ & 1.88 \\
\hline C: HK by HPT after soaking in $0.5 \%$ unsalted miso for $0.5 \mathrm{~h}$ at $55^{\circ} \mathrm{C}$ & $9.13 \mathrm{a}$ & 3.38 & $21.44 \mathrm{c}$ & 3.28 & $34.40 \mathrm{c}$ & 7.02 & $24.18 \mathrm{c}$ & 5.55 \\
\hline D: HK by HPT after soaking in $1.0 \%$ unsalted miso for $0.5 \mathrm{~h}$ at $55^{\circ} \mathrm{C}$ & $11.64 \mathrm{a}$ & 5.91 & $23.63 \mathrm{c}$ & 5.04 & $23.80 \mathrm{~d}$ & 10.72 & $16.71 \mathrm{~b}$ & 3.43 \\
\hline E: HK by HPT after soaking in $2.0 \%$ unsalted miso for $0.5 \mathrm{~h}$ at $55^{\circ} \mathrm{C}$ & $8.68 \mathrm{c}$ & 2.41 & $20.46 \mathrm{c}$ & 1.28 & $22.69 \mathrm{~d}$ & 8.6 & $18.13 \mathrm{~b}$ & 3.99 \\
\hline F: $\mathrm{H} 243$ by HPT after soaking in $0.5 \%$ unsalted miso for $0.5 \mathrm{~h}$ at $55^{\circ} \mathrm{C}$ & $16.50 \mathrm{~b}$ & 1.62 & $26.24 \mathrm{a}$ & 3.5 & $12.90 \mathrm{~b}$ & 0.71 & $21.60 \mathrm{c}$ & 1.8 \\
\hline
\end{tabular}




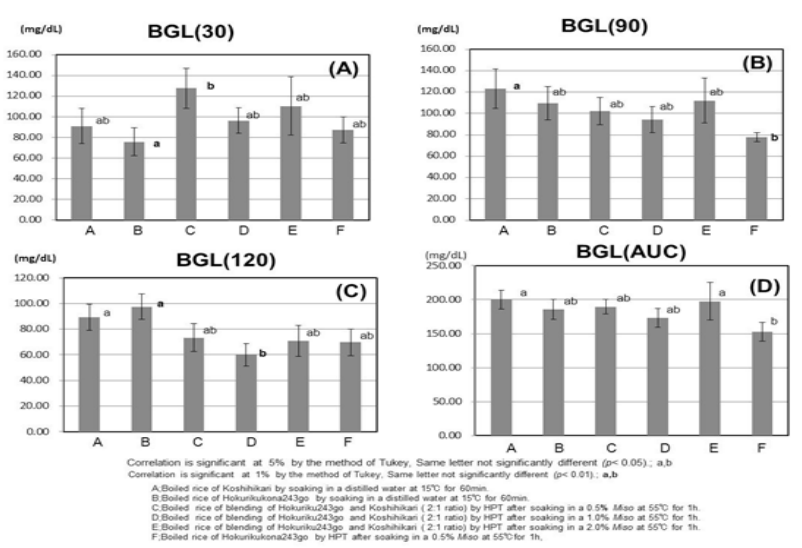

Figure 5: Feeding test of rat

As shown in Figure 5(b), postprandial BGL at 90 min showed significant difference among the rice samples.

As shown in Figure 5(d), postprandial AUC for 120 min of animals fed sample F was significantly lower than that of animals fed the control diet A. Thus, sample F (Hoku243 boiled rice after HPT and soaking in a $0.5 \%$ unsalted miso for $0.5 \mathrm{~h}$ at $55^{\circ} \mathrm{C}$ ) was the most promising to inhibit the postprandial abrupt increase in BGL. In contrast, rice blend samples showed no significant inhibition of abrupt increase of BGL.

Moritaka et al. showed that the AUC for 120 min after eating boiled rice slowly increased by adding agar and the maximum AUC was decreased ${ }^{[33]}$. Folium Mori extracts $\left(150 \mathrm{mg} / \mathrm{kg}\right.$ ) significantly reduced the AUC of GK rat (Goto-Kakizaki rat) ${ }^{[34]}$. RS content of high-amylose corn starch (HAS) doubled after heat-moisture treatment. Short chain fatty acid (SCFA) concentration was higher in HAS groups than ordinary corn starch (OCS) group and the cecal pH was lower in HAS groups than in OCS group ${ }^{[35]}$. The physiological effects of dietary carbohydrates are highly dependent on the rate and extent of digestion and absorption in the small intestine as well as fermentation in the large intestine, which promote human health. Hoku243 seems to be promising in terms of its bio-functionality, including diabetes prevention, because it is associated with a lower BGL as shown in Figure 1.

\section{Tests by human using high-amylose rice and low-amylose rice}

Analysis of expiratory gas after meal: High-amylose rice showed higher hydrogen gas compared with low-amylose one, which means higher resistance to digestion in the small intestine. As shown in Xiao Gaodegree of resistance to digestion measured by the expiratory gas analysis showed marked difference between high-amylose rice and low-amylose one. Expiratory gas analysis will be very useful to search for the high resistant starch food (Figure 6).

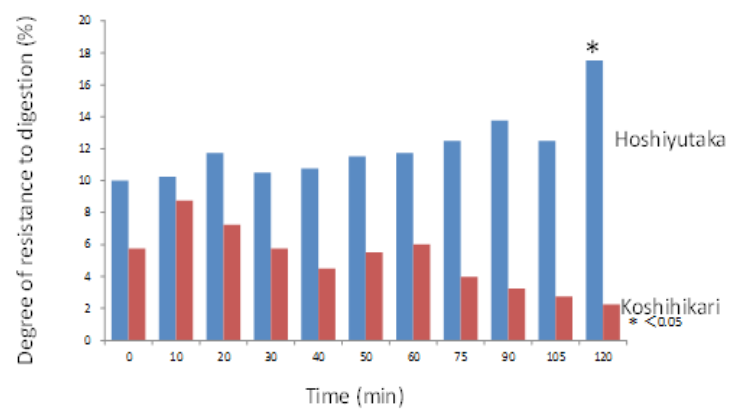

Figure 6: Degree of resistance to digestion measured by the expiratory gas analysis

Change of blood sugar after meal for different rice samples: As shown in figure 7, drastic increase of blood glucose after meal was inhibited significantly in the case of high-amylose rice. The effect was not significant for the inhibition of the increase of blood insulin. High-amylose rice revealed resistance to digestion, which leads to the low GI. It seems to be promising to be effective to prevent diabetes. 
Effects on blood sugar

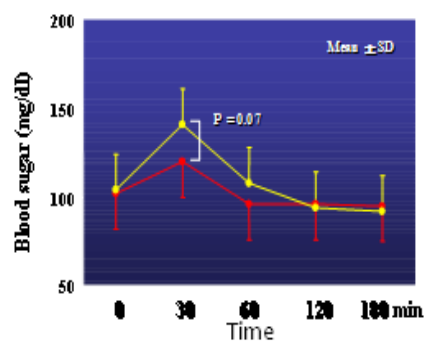

subjects: 10 , age: $28.4 \pm 10,50$ g as sugar

High-anylose - Low-amylose

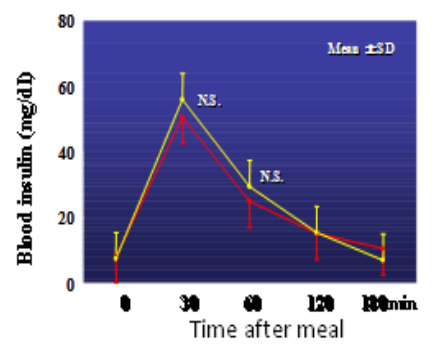

Figure 7: Change of blood sugar after meal for different rice samples

Change in blood GLP-1 after meal: Contents of hormone in digestive organ(GLP-1: glucagon like peptides) were different significantly depending on the amylose of rice sample (Figure 8).

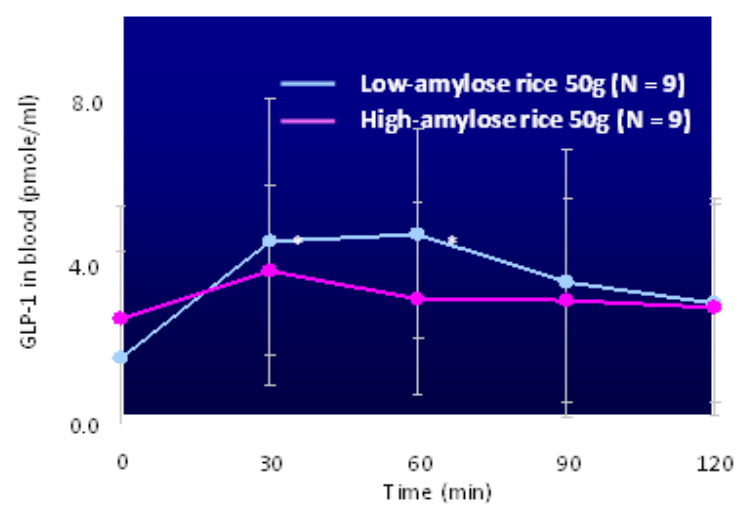

Figure 8: Change in blood GLP-1 after meal

As a research in the future, development of cooking method to improve the eating quality of the high-amylose rice without decreasing resistant starch will be meaningful. Diet test and feeding test using ae mutant rice as materials (rice bread, rice noodle, rice cake, etc.) will be carried out. Experiment of high-amylose rice feeding to diabetes model rats and long term test for rats and human beings would be fruitful. Research for other bio-markers, such as adipocytokines, would be performed.

\section{Conclusions}

Proximate components and gelatinization properties of the high-amylose rice were clarified. Texture and eating qualities of the cooked rice from high-amylose rice were reported. PCR primers were developed to select the high/low amylose rice cultivars. In the case of high-amylose rice, drastic increase of blood glucose and insulin after meals were inhibited. The inhibition was accelerated by the retrogradation of the gelatinized starch. Expiratory gas analysis supported the priority of the high-amylose rice to the ordinary low-amylose rice for the purpose of diabetes prevention.

We developed a new method to treat rice that resulted in a decrease of postprandial BGL. Figure 5 shows that after HPT and soaking in unsalted miso, ingestion of the treated boiled rice grains results in a decrease in postprandial BGL. Ae mutant rice, Hoku243, is a suitable cultivar because its starch contains amylopectin, which consists of long-chain glucans. The addition of glucose, glutamic acid, and dietary fibers by soaking in unsalted miso suspension increased the taste and hardness of boiled rice. The texture of Hoku2 43 boiled rice grains became harder, but sticky, which made Hoku243 acceptable in terms of palatability and bio-functional in terms of delaying the digestion. It is now possible to produce palatable and bio-functional boiled rice grains by HPT and soaking in unsalted miso.

\section{Acknowledgement}

We express our gratitude to the Council of Cabinet for the financial support for our research (Development of Bio-functional Food for Next Generation, SIP). And we deeply thank to the Committee of the third International Symposium on Rice and Disease Prevention. 


\section{References}

1. Yang, C.Z., Shu, X.L., Zhang, L.L, et al. Wu: Starch properties of mutant rice high in resistant starch. (2006) J Agric Food Chem 54(2): 523-528.

2. Goddard, M.S., Young, G., Marcus, R. The effect of amylose content on insulin and glucose responses to ingested rice. (1984) Am J Clin Nutr 39(3): 388-392.

3. Kang, H.J., Hwang, I.K., Kim, K.S., Comparative structure and physicochemical properties of Ilpumbyeo, a high-quality Japonica rice, and its mutant, Suwon 464. (2003) J Agric Food Chem 51(22): 6598-6603. 4. Kang, H.J., Hwang, I.K., Kim, K.S., et al. Comparative structure and physicochemical properties of Ilpumbyeo, a high-quality Japonica rice, and its mutant, Suwon 464. (2003) J Agric Food Chem 51(22): 6598-6603.

5. Goda, T., Kajiya, Y., Suruga, K., et al. Availability, fermentability, and energy value of resistant maltodextrin: modeling of short-term indirect calorimetric measurements in healthy adults. (2006) Am J Clin Nutr 83(6): 1321-1330.

6. Miyazato S1, Nakagawa C, Kishimoto Y, et al. Promotive effects of resistant maltodextrin on apparent absorption of calcium, magnesium, iron and zinc in rats. (2010) Eur J Nutr 49(3): 165-171.

7. Nishi, A., Nakamura, Y., Tanaka, N., et al. Biochemical and genetic analysis of the effects of amylose-extender mutation in rice endosperm. (2001) Plant Physiol 127(2): 459-472.

8. Nakamura, S., Satoh, H., Ohtsubo, K. Development of formulae for estimating amylose content, amylopectin chain length distribution, and resistant starch content based on the iodine absorption curve of rice starch. (2015) Biosci Biotechnol Biochem 79(3): 443-455.

9. Nakamura, S., Satoh, H., Ohtsubo, K. Palatable and bio-functional wheat/rice products developed from pre-germinated brown rice of super-hard cultivar EM10. (2010) Biosci Biotechnol Biochem 74(6): 1164-1172.

10. Nakamura, S., Satohm H., Ohtsubo, K. Characteristics of pregelatinized ae mutant rice flours prepared by boiling after preroasting. (2011) J Agric Food Chem 59(19): 10665-10676.

11. Nilsson, A.C., Ostman, E.M., Granfeldt, Y., et al. Effect of cereal test breakfasts differing in glycemic index and content of indigestible carbohydrates on daylong glucose tolerance in healthy subjects 1,2,3. (2008) Am J Clin Nutr 87(3): 645-654.

12. Henry, C.J., Lightowler, H.J., Tydeman, E.A., et al. Use of low-glycaemic index bread to reduce 24-h blood glucose: implications for dietary advice to non-diabetic and diabetic subjects. (2006) Int J Food Sci Nutr 57(3-4): 273-278.

13. Nakamura, S., Ohtsubo K. Influence of physicochemical properties of rice flour on oil uptake of tempura frying batter. Biosci. (2010) Biotechnol Biochem 74(12): 2484-2489.

14. Momose, N. Goto, H. Hayase, T., et al. Effects of miso (soybean paste) on postprandial blood sugar levels. (2010) Nippon Shokuhin Kagakukogaku Kaishi 57(2): 63-69.

15. Hayashi, R. Application of high pressure to food processing and preservation: philosophy and development. (1989) Engineering and Food 2: 815-826.

16. Kimura, K., Ida, M., Yoshida, Y., et al. Comparison of keeping quality between pressure-processed jam and heat-processed jam: Changes in flavor components, hue, and nutrients during storage. (1994) Biosci Biotechnol Biochem 58(8): 1386-1391.
17. Yun, D., Yu, Z., Wenjuan, Y., et al. Effect of hydrostatic high pressure pretreatment on flavor volatile profile of cooked rice. (2013) J Cereal Sci 58(3): 1-9.

18. Kato, T., Katayama, E., Matsubara, S., et al. Release of allergenic proteins from rice grains induced by high hydrostatic pressure. (2000) J Agric Food Chem 48(8): 3124-3129.

19. Kinefuchi, M., Sekiya, M., Yamazaki, A., et al. Accumulation of GABA in brown rice by high pressure treatment. (1999) Nippon Shokuhin Kagaku Kogaku Kaishi 46(5): 323-328.

20. Yamakura, M., Haraguchi, K., Okadome, H., et al. Effects of soaking and high-pressure treatment on the quality of cooked rice. (2005) J Appl Glycosci 52: 85-93.

21. Maeda, S., Kazama, Y., Kobayashi, A., et al. Improvement of palatability and prevention of abrupt increases in postprandial blood glucose levels by Hokurikukona243 after high pressure treatment. (2015) J Appl Glycosci 62: 127-134.

22. Scalbert, A., Manach, C., Morand, C., et al. Dietary polyphenols and the prevention of diseases. (2005) Crit Rev Food Sci Nutr 45(4): 287-306.

23. AOAC. Official Methods of Analysis of AOAC International. (1995a) Method 925.10: Solids and Moisture in Flour-Air Oven Method-Final Action.

24. AOAC. Official Methods of Analysis of AOAC International. (1995b) Method 920.87: Protein (Total) in Flour-Final Action.

25. AOAC. Official Methods of Analysis of AOAC International. (1995c) Method 922.06: Fat in Flour-Acid Hydrolysis Method-Final Action.

26. AOAC. Official Methods of Analysis of AOAC International. (1995d) Method 923.03: Ash of Flour-Direct Method-Final Action.

27. Juliano, B. O. A simplified assay for milled-rice amylose. (1971) Cereal Sci Today 16(11): 334-360.

28. Nakamura, S., Nakano, Y., Satoh, H., et al. Improved palatability and bio-functionality of super-hard rice by soaking in a barley-Koji miso suspension. (2013) Biosci Biotechnol Biochem 77(12): 2419-2429.

29. Okadome, H., Toyoshima, H., Ohtsubo, K. Multiple measurements of physical properties of individual cooked rice grains with a single apparatus. (1999) Cereal Chem 76(6): 855-860.

30. Toyoshima, H. Okadome, H., Ohtsubo, K., et al. Cooperative test on the small-scale rapid method for the gelatinization properties test of rice flour with a RVA. (1997) Nippon Shokuhin Kagaku Kogakukaishi, 44(8): 579-584.

31. Nakamura, S. Okadome, H., Yoza, K., et al. Differentiation and search for palatability factors of world-wide rice grains by PCR method. (2004) Nippon Nogeikagaku Kaishi 78(89): 764-779.

32. Ohtsubo, K., Nakamura, S. Cultivar identification of rice by polymerase chain reaction method and its application to processed rice products. (2007) J Agric Food Chem 55(4): 1501-1509.

33. Takeda, Y., Hizukuri, S., Juliano, B.O. Purification and structure of amylose from rice starch. (1986) Carbohydr Res 148(2): 299-308.

34. Moritaka, H., Nakanishi, Y., Fuwa, Y., et al. Effects of agar on thermal property, sensory characteristic and glycemic index of cooked rice. (2012) Nippon Chori Kagaku Kaishi 45: 115-122.

35. Iizuka, Y., Sakurai, E., Tanaka, Y. Antidiabetic effect of folium mori in GK rats. (2001) Yakugaku Zasshi 121(5): 365-369.

36. Saito, K., ito, T., Kuribayashi, T., et al. Effect of raw and heat-moisture treated high-amylose corn starch on fermentation by the rat cecal bacteria. (2001) Starch 53(9): 424-430.
Ommega Online Publishers

Journal Title: Journal of Diabetes and Obesity (JDO)

Journal Short Name: J diabetes Obes
Journal ISSN: 2356-0494

E-mail: diabetes@ommegaonline.com

Website: www.ommegaonline.com 